\title{
STORED ENERGY OF PLASTIC DEFORMATION IN TUBE BENDING PROCESSES
}

\author{
Z. ŚLODERBACH* and J. PAJAZK \\ Opole University of Technology \\ Faculty of Applications of Chemistry and Mechanics \\ 45-036 Opole, ul. Luboszycka 7, POLAND \\ E-mail: z.sloderbach@po.opole.pl
}

\begin{abstract}
The paper presents an aproximate analytic method for determination of the stored energy of plastic deformation during cold bending of metal tubes at bending machines. Calculations were performed for outer points of the tube layers subjected to tension and compression (the points of maximum strains). The percentage of stored energy related to the plastic strain work was determined and the results were presented in graphs. The influence and importance of the stored energy of plastic deformation on the service life of pipeline bends are discussed.
\end{abstract}

Key words: plastic deformation, tube bending, stored energy, austenitic steel, boiler steel.

\section{Introduction}

In Śloderbach and Rechul (2006) the authors specified a particular form of thermodynamic potential of free energy for a thermoplastic body with isotropic hardening, and derived equations for an analytic determination of the stored energy of plastic deformation (SEPD), ability and rate of energy storage, for example in cold bending of metal tubes for bends of pipelines or other tube installations. The relationship in the form of thermodynamic potential of free energy was derived according to the classical thermodynamics of irreversible processes (see e.g., Buchdahl, 1996; Perzyna, 1978; Raniecki and Sawczuk, 1975; Raniecki, 1977; Śloderbach, 1983; Śloderbach and Rechul, 2006) in the material description using macroscopic internal parameters. A body model with isotropic hardening was assumed for calculations, because quasistatic bending of metal tubes at bending machines (wrapping at the rotational former) (Franz, 1961; 1969) was not an example of cyclic fatigue loading. Cold bending of metal tubes at bending machines for bends of pipelines or other tube installations in energetic devices is a quasiisothermal process $(\mathrm{T} \approx$ const.). Here we consider the known ideas of SEPD and choose the best one taking the latest tests results into account (see e.g., Chrysochoos et al. 1989; 1989; 1992; Oliferuk et al. 1993; 1995; 1996 and Oliferuk, 1997).

The stored energy of plastic deformation SEPD can be useful in evaluation of the material state and the state of tube bending process at bending machines. Cold bending of metal tubes, especially in the layers subjected to tension, leads to destruction and size reduction of the initial crystalline structure. The existing structures of grain boundaries are subjected to failure and breaking. Thus, we obtain a greater number of grain boundaries, and their surface increases. It means that it is necessary to take into account changes in the crystalline structure of a metal during plastic deformation, especially changes leading to an increase of dislocation density and high reduction of grain size caused by the formation of a substructure. On the other hand, SEPD initiates and intensifies matter diffusion processes along the grain boundaries. Such phenomena reduce high-temperature diffusion creep resistance of metals and alloys, and that kind of creep belongs to the main causes of premature damages of materials. A description and determination of the quantity of SEPD could be helpful in the analysis and estimation of productive reliability and repairs of elements of devices for power engineering, especially those in which large plastic deformations formed at the stage of manufacturing. A correct determination of SEPD could be helpful in the analysis of mechanisms and causes of damages, and in elaboration of methods of damage prevention at the designing stage, development of technology of production and repairs of many machine elements.

\footnotetext{
* To whom correspondence should be addressed
} 
In Śloderbach (1983), Śloderbach and Rechul (2006) it is shown that SEPD is equal to a change of internal energy of the body resulting from plastic deformation, and it is equal to enthalpy of plastic deformation. It is obvious that the energy balance of the plastic deformation process is described by the first law of thermodynamics. Since processes of plastic deformation of metals and alloys are irreversible, it is necessary to satisfy also the second law of thermodynamics for irreversible processes, the so-called dissipation rule (see e.g., Buchdahl, 1996; Perzyna, 1978; Śloderbach 1983; Śloderbach and Rechul, 2006).

The results obtained in this research confirm the known phenomena and effects, namely: SEPD increases and its ratio to the plastic strain work and ability to energy storage decrease as the plastic strain increases (in the considered case, it means increase of the bending angle).

\section{Geometric-analytic description of tube bending}

An analytic-geometric description and analysis of the process concern tube bending by wrapping at the rotating former with the use of a mandrel or without it, keeping $d_{w} \cong$ const (permissible ovalization is $6 \%$, according to EN 448 of 1993). An analytic description of deformation is limited to determination of the plastic strain state with the method of kinematically permissible strain fields (Marciniak, 1971; Śloderbach, 1999; Śloderbach and Rechul, 2000), because elastic strains are very small and they can be omitted. Taking into account the experimental data available from (Franz, 1961) and those derived in Śloderbach (1999) the generalized logarithmic components of the strain state including also displacement of the neutral axis of plastic bending $y_{0}$ (see Fig.1) can be written as

$$
\phi_{1} \cong \lambda_{i} \ln \frac{2\left(R-y_{0}\right) \pm\left(d_{i} \cos \beta_{i} \pm 2 y_{0}\right)\left(\cos (k \alpha)-\cos \left(k \frac{\alpha_{g}}{2}\right)\right)}{2\left(R-y_{0}\right)}, \varphi_{2} \cong \ln \frac{d_{i}}{d_{z}}, \varphi_{3} \cong \ln \frac{g_{i}}{g_{0}}
$$

Expressions (2.1) are the main quantities describing the strain state of the tube subjected to bending. Namely, if the top and external points of the tube are considered, then $\cos (k \alpha)=1$ and $\cos \beta_{i}=1$. If displacement of the neutral axis of plastic bending is neglected, $\left(y_{0}=0\right)$ should be substituted.

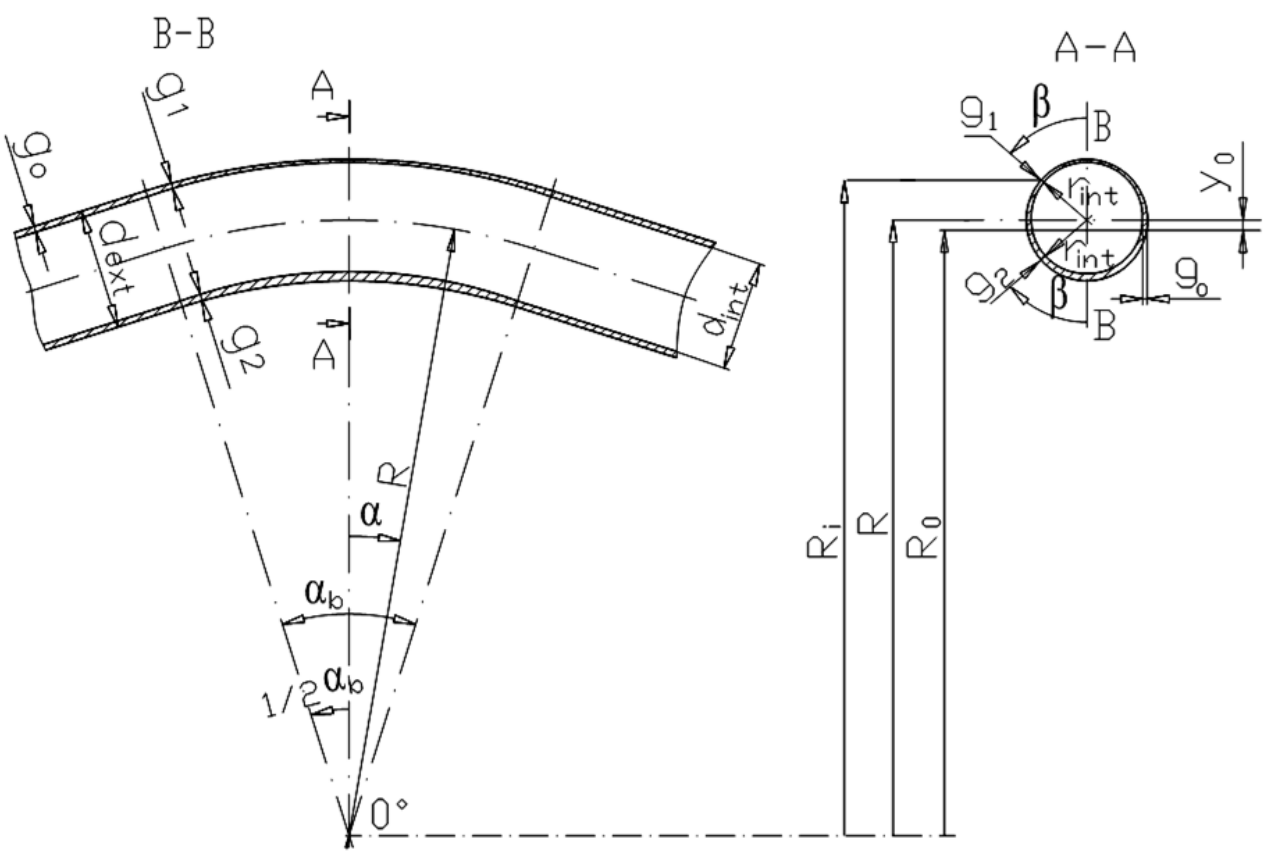

Fig.1. Geometrical quantities involved in the pipe-bending processes description according to Sloderbach and Rechul (2000). 
The expression for strain intensity can be written as Marciniak (1971)

$$
\varphi_{(i)}=\sqrt{\frac{2}{3}\left(\varphi_{1}^{2}+\varphi_{2}^{2}+\varphi_{3}^{2}\right)} .
$$

Expressions (2.1) and (2.2) can be used for the description of the strain state of the tube subjected to bending at the top, $\cos (k \alpha)=1$ and external, $\cos \beta=1$ points of the layers subjected to tension or compression,

where: $\varphi_{1}, \varphi_{2}, \varphi_{3}$ - logarithmic components of plastic strains, $\varphi_{(i)}$ - intensity of logarithmic plastic strains.

The following quantities are included into Eqs (2.1) and in Fig.1 they have the following meaning: $g_{0}$ and $g_{i}$ - initial thickness of the tube, and actual thickness of the bend wall in the bending zone, $R$ - suitable bending radius, $R_{i}$ and $R_{0^{-}}$large active actual bending radius connected with longitudinal strain and the radius determining the actual position of the neutral layer, $r_{i}$ - small active actual radius of the bend in the bending zone, $r_{i}=r_{\mathrm{int}}+g_{i}$ and $d_{i}=2 r_{i}$, $r_{\text {ext }}$ and $d_{\text {ext }}$ radius and external diameter of the tube subjected to bending, respectively $d_{\text {ext }}=2 r_{\text {ext }}$, $r_{\text {int }}$ and $d_{\text {int }}$ - radius and internal diameter of the tube, $d_{\text {int }}=2 r_{\text {int }}$,

$y_{0}$ - displacement of the neutral layer of plastic bending, $\alpha$ and $\beta$ - angles of the point position in the bending zone, $\alpha_{g}$ - bending angle measured in the bending zone; in this zone $\alpha_{g}=\alpha_{0}$, where: $\alpha_{0^{-}}$bend angle (angle of the former rotation), $\beta_{i^{-}}$angles of circulation of layers subjected to tension and compression in the bend $\beta_{i} \in\left\langle 0,90^{\circ} \pm \beta_{0}\right\rangle$, and: $\sin \beta_{0}=y_{0} / r_{\mathrm{ext}}$,

where $\beta_{0}-$ angular range of displacement of the bending neutral axis, index $i=1$ and sign ( + ) in Eqs (2.1) are related to the layers subjected to tension, index $i=2$ and sign (-) in Eqs (2.1) are related to the layers subjected to compression.

And additionally:

$k$ - technological-material coefficient defined according to the test results, determining the bending zone range so that $k \alpha_{g}=180^{\circ}$. In theory, $k \in\langle 1 ; \infty\rangle$. For practical purposes we can assume that $k \in\langle 1 ; \sigma\rangle$. From the known test results it appears that we can assume $k \in\langle 1 \div 3\rangle$, (see: Franz, 1961; Śloderbach, 1999; Śloderbach and Rechul, 2000). For example, for bends with the bending angle $180^{\circ}$, the coefficient $k$ expresses a ratio of the bend angle $\alpha_{0}$ to the actual bending angle $\alpha_{g}$, i.e., $k \cong \alpha_{0} / \alpha_{g}$. When $\alpha_{0}=180^{\circ}$, then $\alpha_{0}=k \alpha_{g}=180^{\circ}$,

$\lambda_{i^{-}}$correction coefficient (technological - material) of strain distribution in the layers subjected to tension $(i=1)$ and compression $(i=2)$, determined according to test for $\lambda_{1} \cong 1$ and $\lambda_{2} \in<0 ; 1>$. For most known experiments, we can assume that $\lambda_{2} \approx 0.5$ (Franz, 1961; Śloderbach, 1999; Śloderbach and Rechul, 2000).

\section{Analytical description of experimental data for austenitic steel}

In many works on the phenomena and effects in energy storage processes (see Gadaj et al. 1996; Oliferuk et al. 1993; 1995; 1996 and Oliferuk, 1997) austenitic steel 00H19N17Pr was tested. The tested steel had grain thickness $A=8 \mu \mathrm{m}$ and $B=80 \mu \mathrm{m}$. In the present paper we consider only the steel of grain thickness $80 \mu \mathrm{m}$. For this steel, an almost linear dependence (except for the initial deformation stage) of the stored energy and the square of yield stress was obtained (see e.g., Oliferuk et al., 1996 and Oliferuk, 1997).

The experimental hardening curve obtained during uniaxial tension of the steel was approximated with a very good accuracy with the Swift equation (Marciniak, 1971) 


$$
\sigma=Y=C\left(\varphi_{0}+\varphi_{(i)}\right)^{n}
$$

of the following explicit form

$$
\sigma=1275.1\left(0.0214+\varphi_{1}\right)^{0.5359}[\mathrm{MPa}]
$$

where: the coefficient of the square regression $\hat{R}^{2} \approx 99.75 \%$,

$\sigma=Y$ - stress equal to the yield point under uniaxial tension [MPa],

$C$ - material constant: $C \approx 1275.1 \mathrm{MPa}$,

$\varphi_{\sigma}$ strain corresponding to the initial yield point; $\varphi_{\sigma} \approx 0.0214$,

$\varphi_{I^{-}}$logarithmic longitudinal plastic strain (along the axis),

$\varphi_{(i)^{-}}$intensity of the logarithmic plastic strain,

$n$ - coefficient of the material hardening, $n \approx 0.5359$.

In order to determine the stored energy of plastic deformation where SEPD $\equiv E_{s}$ it is assumed like in Bever et al., 1973; Oliferuk et al., 1996; Śloderbach and Rechul, 2006 that the expression for the stored energy can be aproximatelly written as a linear dependence on the square of yield stress

$$
\rho_{0} E_{s}=B_{0}\left[Y^{2}\left(\varphi_{(i)}, T\right)-Y_{0}^{2}(T)\right]\left[J / m^{3}\right]
$$

where $B_{0}$ is the coefficient of proportionality (a material constant), $\left[B_{0}\right]=\mathrm{Pa}^{-1}$.

Let us note that Eq.(3.2) is equal to the following expression

$$
E_{s}=\frac{2 B_{0}}{\rho_{0}} \int_{0}^{\varphi_{(i)}} Y(\xi, T) \frac{\partial Y(\xi, T)}{\partial \xi} d \xi
$$

In the case under consideration, the condition satisfying the dissipation rule, derived in Ślodrebach and Rechul (2006) is as follows

$$
Y\left(\varphi_{(i)}, T\right)-Y_{0}(T) \leq \frac{1}{2 B_{0}} \varphi_{(i)}
$$

In the papers (Gadaj et al., 1996; Oliferuk et al., 1993; 1995; 1996 and Oliferuk, 1978), for the tested austenitic steel $0019 \mathrm{~N} 17$ Pr the coefficient $B_{0}$ takes the values: $B_{0} \approx 8.8 \times 10^{-5}\left[\mathrm{MPa}^{-1}\right.$ or $B_{0} \approx 88 \times 10^{-}$ ${ }^{12}[\mathrm{~Pa}]^{-1}$ then the dissipation rule (3.4) is satisfied. Density $\rho_{0}$ for that steel is taken from the tables and it is $\rho_{0} \approx 7.8 \times 10^{3}\left[\mathrm{~kg} / \mathrm{m}^{3}\right]$. In the case of tube bending and for bending temperature rise $\sim 40 \mathrm{~K}$, the estimated maximum energy of the thermostatic piezocaloric effect (Raniecki, 1977; Śloderbach, 1983) is about $0.26 \mathrm{~J} / \mathrm{g}$.

The results of precise approximations and calculations of density of the stored energy of plastic deformation SEPD per mass unit are shown in Fig.2. The graph was obtained from expressions (3.2) or (3.3), after introduction of Eq.(3.1). 


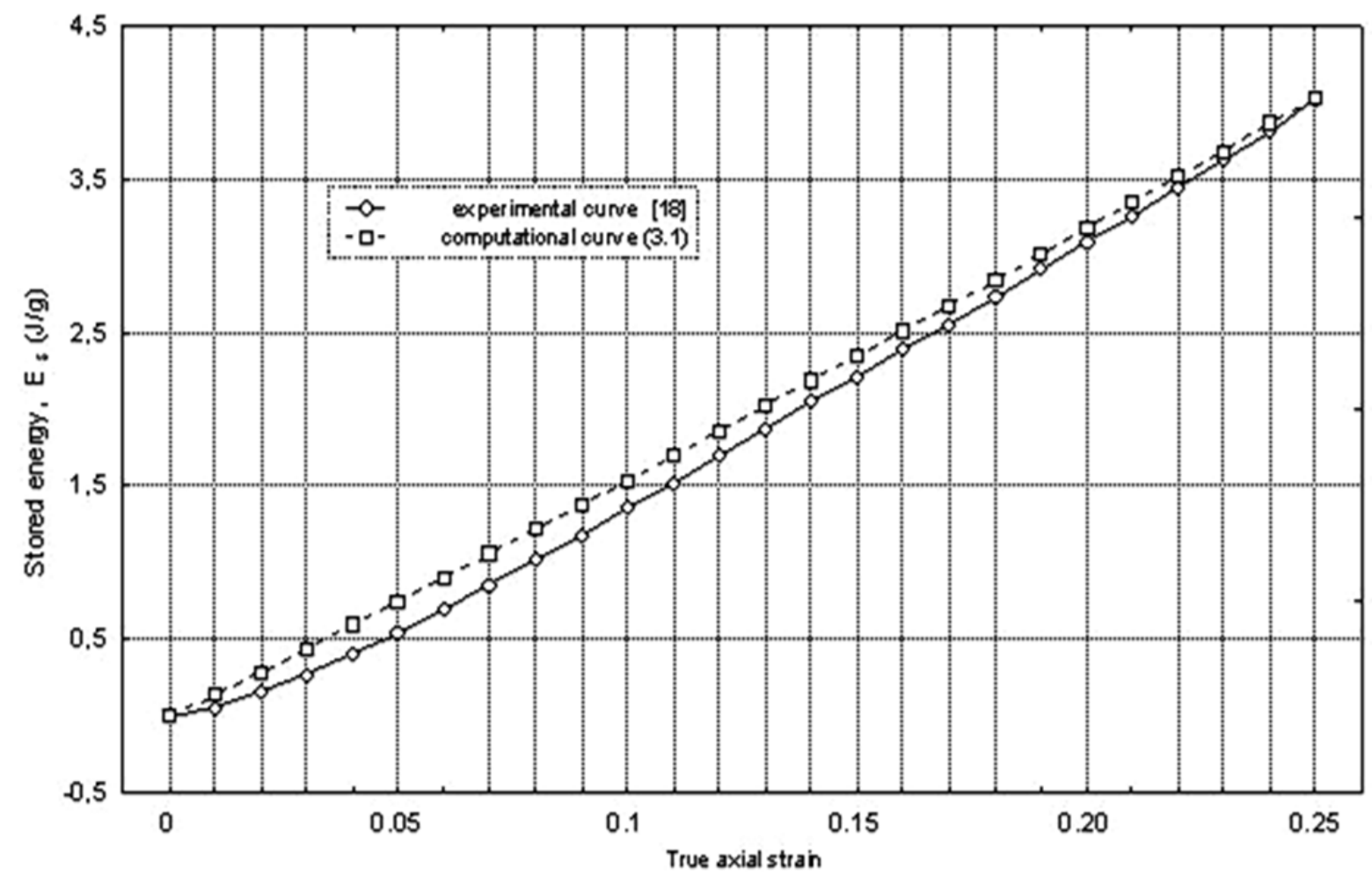

Fig.2. Approximation of the stored energy curve $E_{s}$ obtained experimentally in Oliferuk (1977) with expressions (3.1)-(3.3).

At the experimental curve (Fig.2) one can notice a small decrease of $E_{s}$ within the strain range to $5 \%$. This reduction is a result of accommodation of non-compatible elastic-plastic strains of the adjacent grains, connected with kinematic hardening (Bauschinger effect) and formation of the field of internal microstresses of Kadaszewicz-Novożiłow (see Chrysochoos et al., 1989; 1989; 1992; 1964). Accommodation of noncompatible elastic-plastic strains can take place when an additional amount of the dissipated energy of plastic strain is present. The proposed expression (3.1) for description of the hardening curve of austenitic steel 00H19N17Pr does not include the kinematic hardening effect because of a lack of experimental data for this steel. The analytic description (3.1) includes only isotropic hardening which is of a great importance under great strains occurring while bending metal tubes at bending machines.

\section{Aproximate analytic determination of stored energy values in metal tubes bending}

According to Adam et al. (1978), Bever et al. (1973), Chrysochoos et al. (1989; 1989; 1992; 1964), Oliferuk et al. (1993; 1995; 1996; 1997), Soós and Badea (1997), Śloderbach and Rechul (2006) SEPD depends on many factors, for example a degree of plastic deformation, deformation rate, temperature of the deformed body, stress state, crystallographic structure, temperature, deformation history and deformation rate history, temperature history and history of temperature variation rate, chemical composition. In metals and alloys it is connected with formation of various defects in the crystal lattice, for example its deformation and orientation change, damages of grains and its boundaries, formation of pile-up of dislocations and vacancies, deformation of atomic layers. In metals and alloys, this energy causes also dynamic and static recovery and recrystallization.

For determination of SEPD while metal tube bending at a bending machine, austenitic steel $00 \mathrm{H} 19 \mathrm{~N} 17 \mathrm{Pr}$ was applied. Its grain thickness was $80 \mu \mathrm{m}$. The same steel was tested in Gadaj et al. (1996), Oliferuk et al. (1993; 1995; 1996), Oliferuk (1997). SEPD was determined according to Eqs (3.1), (3.2) or (3.3), where $\xi \equiv \varphi_{(i)}$ was introduced. 
Plastic strain work per mass unit, calculated according to measures for true (logarithmic) strains is expressed by the following equation (Marciniak, 1971)

$$
W^{p}=\frac{1}{\rho_{0}} \int_{o}^{\varphi_{(i)}} \sigma_{(i)} d \varphi_{(i)}=\frac{1}{\rho_{0}} \int_{0}^{\varphi_{(i)}} Y\left(\varphi_{(i)}, T\right) d \varphi_{(i)} .
$$

Let us substitute (3.1) to (4.1), and integrate the obtained formula. Then, we have

$$
W^{p}=\frac{C}{\rho_{0}(n+1)}\left[\left(\varphi_{0}+\varphi_{(i)}\right)^{n+1}-\varphi_{0}^{n+1}\right] .
$$

Tube bending at bending machines is a quasistatic process, where deformation rates are about $\left(10^{-4}-\right.$ $\left.10^{-3}\right) \mathrm{s}^{-1}$, and temperature change for the tube is about $\sim 10 \div 40 \mathrm{~K}$ because of plastic strains. In such a case we assume that such temperature change does not influence the hardening curve for the deformed material. Such a process can also be called quasiisothermal, then $(T \approx$ const). We can distinguish cold bending in the ambient temperature, or bending at higher temperatures [hot bending, semi-hot bending or bending with preheating, (see e.g. Kocańda, 1998; Marciniak and Konieczny, 1987)], but in practice we can neglect temperature changes. From the practical point of view, it is possible to neglect all the thermal effects connected with temperature changes during bending. Thus

$$
\frac{\partial Y\left(\varphi_{(i)}, T\right)}{\partial T} \cong 0 \quad \text { and } \quad \frac{\partial W^{p}\left(\varphi_{(i)}, T\right)}{\partial T} \cong 0 .
$$

After the application of Eqs (2.1), (2.2), (3.1), (3.3) and (4.1) the results of numerical calculations for the tube $\phi 44.5 \times 4.5 \mathrm{~mm}$, bent at the angle $\left(\alpha_{0}=k \alpha_{g}=180^{\circ}\right)$ with the bending radius $R=80 \mathrm{~mm}\left(R \approx 1,8 \times d_{z}\right)$ and for $\left(y_{0}=0\right)$ were presented in Figs 3-6. The tube was made of austenitic steel 00H19N17 Pr, the grain size was $80 \mu \mathrm{m}$, and density $\rho_{0} \approx 7.8 \times 10^{3}\left[\mathrm{~kg} / \mathrm{m}^{3}\right]$.

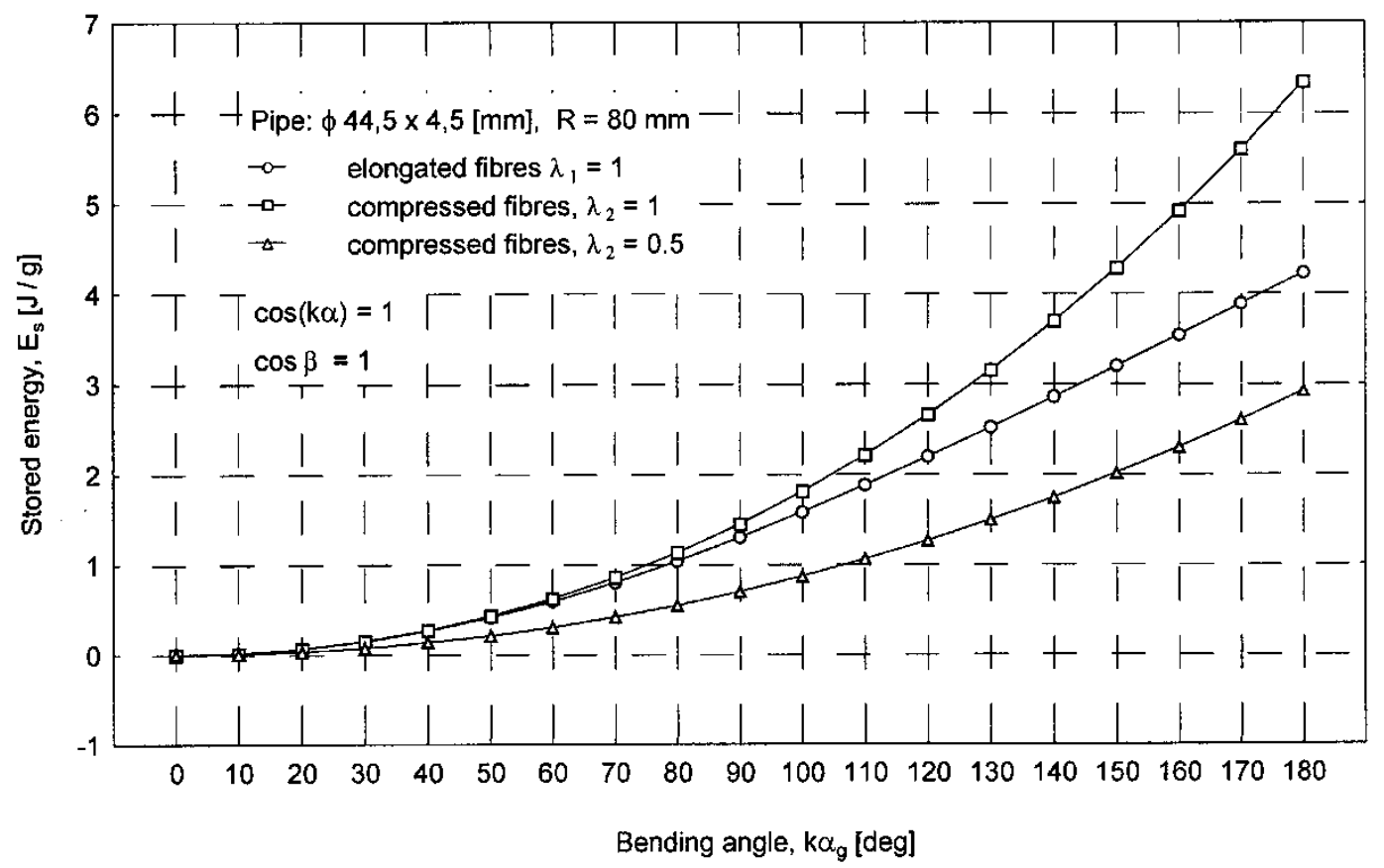

Fig.3. Plots of the stored energy of strain hardening for stretched and compressed layers as a function of bending angle $k \alpha_{g}$ shown in terms of true strain for bending pipes made of austenitic steel $00 \mathrm{H} 19 \mathrm{~N} 17 \mathrm{Pr}$ with the grain size of $80 \mu \mathrm{m}$. 


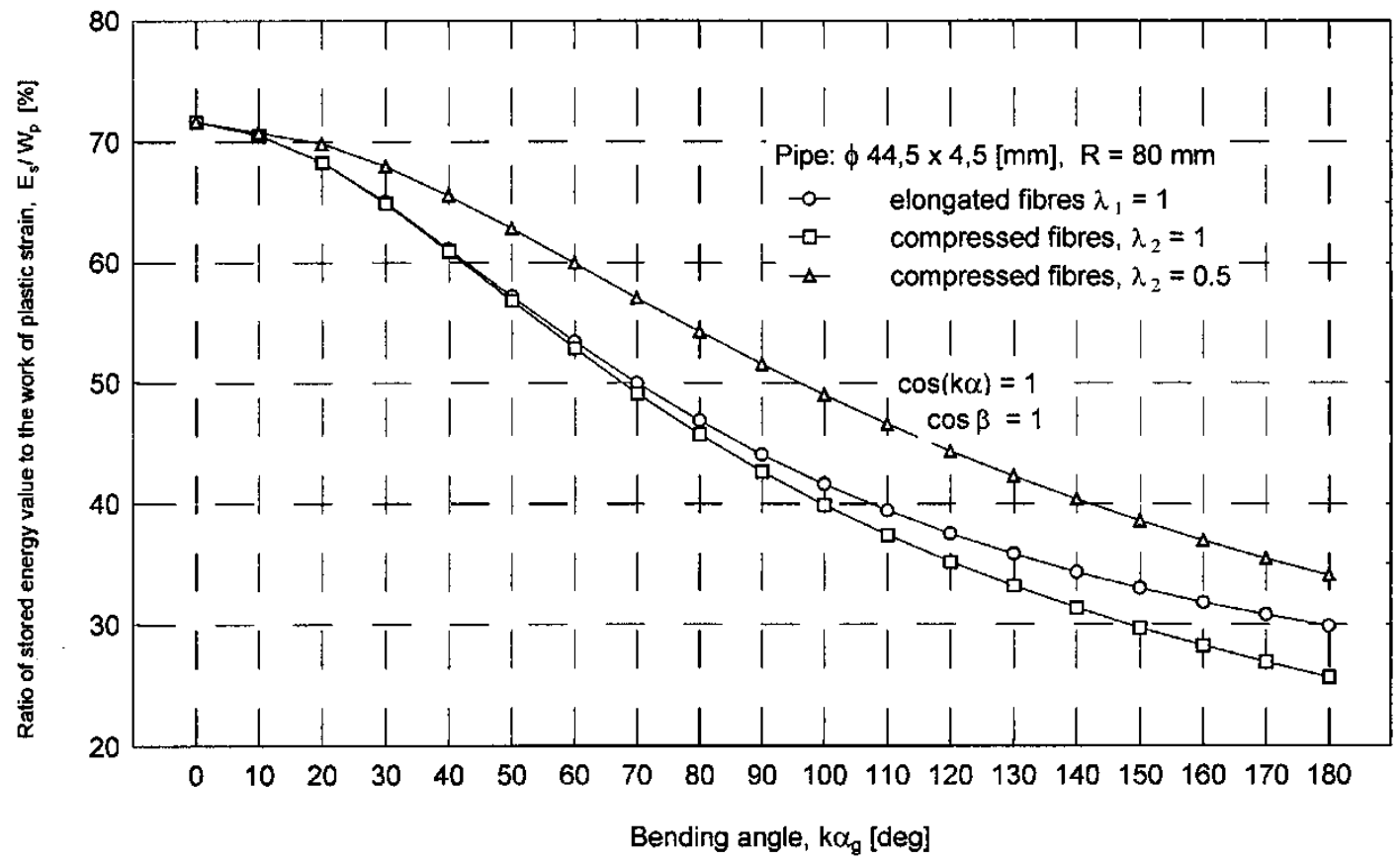

Fig.4. Plots of the ratio of the stored energy value to the work of plastic strain value for stretched and compressed layers as functions of bending angle $k \alpha_{g}$ expressed in terms of true strain in bending pipes made of austenitic steel $00 \mathrm{H} 19 \mathrm{~N} 17 \mathrm{Pr}$ with the grain size of $80 \mu \mathrm{m}$.

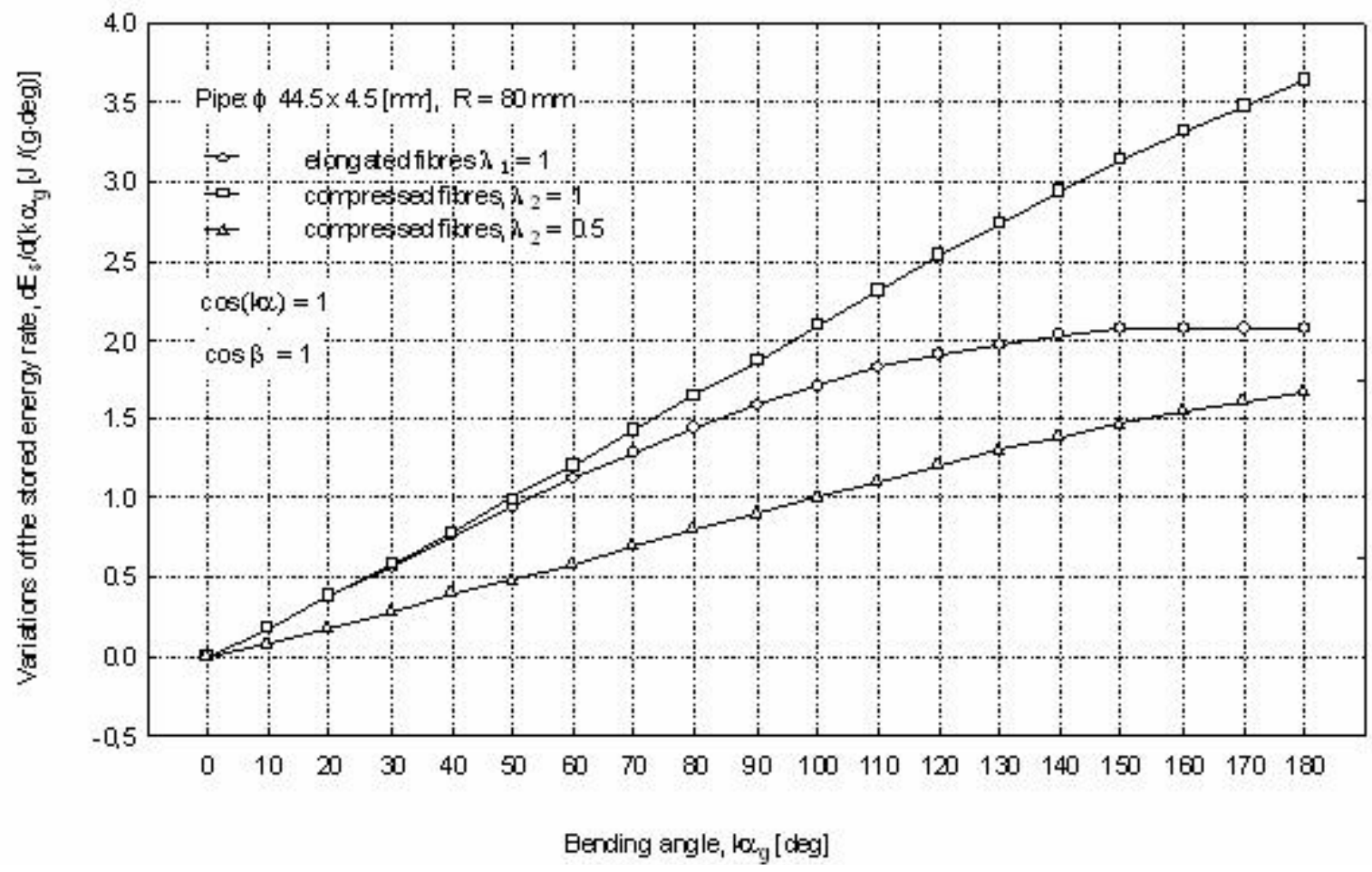

Fig.5. Plots of the stored energy rate for stretched and compressed layers as functions of bending angle $k \alpha_{g}$ expressed in terms of true strain, bending pipes made of austenitic steel $00 \mathrm{H} 19 \mathrm{~N} 17 \mathrm{Pr}$ with the grain size of $80 \mu \mathrm{m}$. 


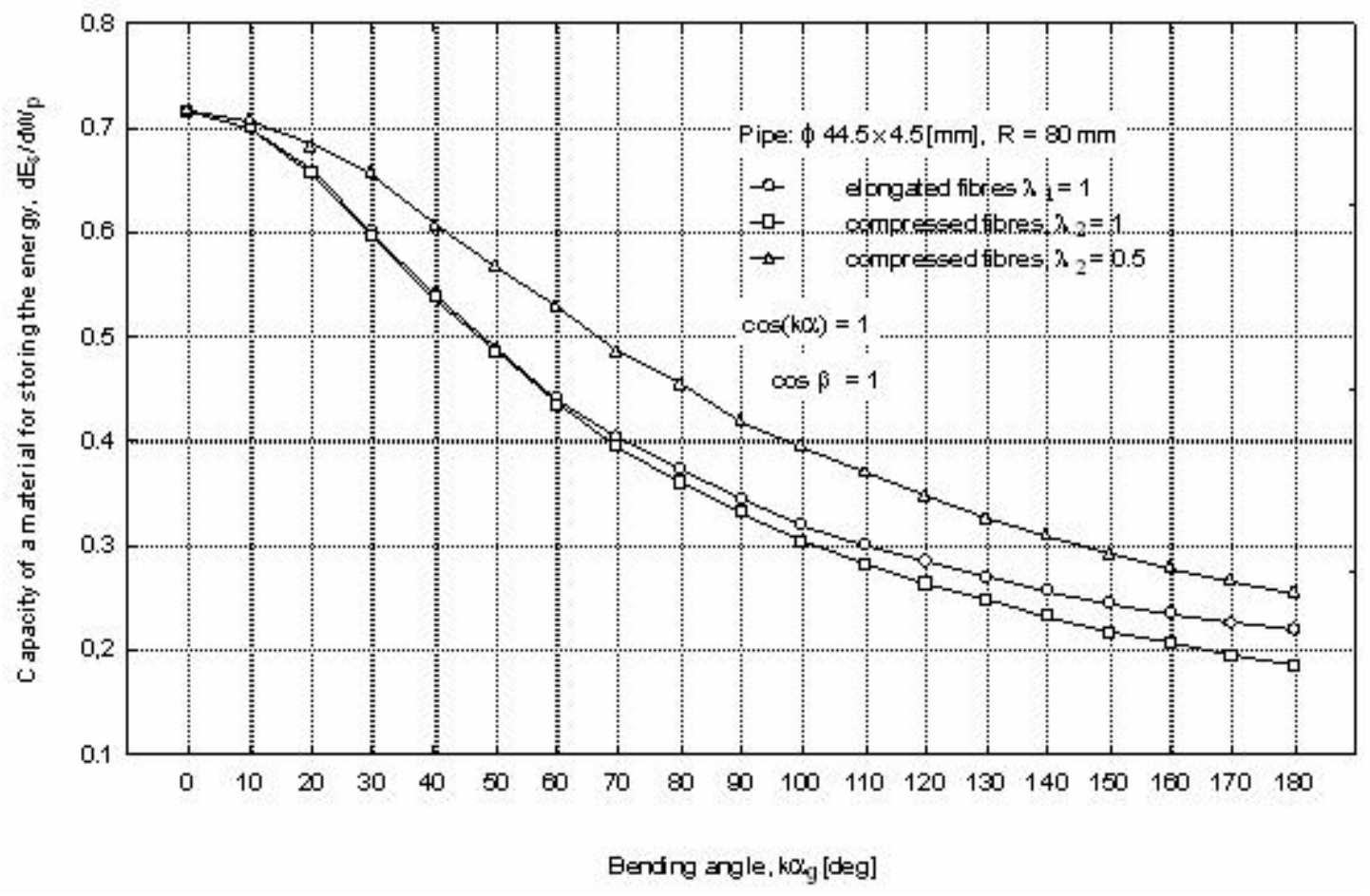

Fig.6. Plots showing capacity of a material for storing the energy for stretched and compressed layers as functions of bending angle $k \alpha_{g}$ expressed in terms of true strain in bending pipes made of austenitic steel $00 \mathrm{H} 19 \mathrm{~N} 17 \mathrm{Pr}$ with the grain size of $80 \mu \mathrm{m}$.

Figure 3 shows that the values of SEPD in the layers subjected to tension-compression increase as the bending angle $k \alpha_{g}$ increases, and they reach their maximum for $k \alpha_{g}=180^{\circ}$, which means the end of the bending zone range. It also appears that the values of SEPD in the layers subjected to compression for $\lambda_{2}=1$ are greater, and for $\lambda_{2}=0.5$ are less than in the layers subjected to tension for $\lambda_{1}=1$. It results from the geometry of strain distribution while tube bending at bending machines.

From deformation description it appears that in absolute values for strain components and strain intensity the following inequalities take place for $\lambda_{1}=1$

when

$$
\left|\varphi_{1 \text { com }}\right|_{\lambda_{2}=1}>\left|\varphi_{1 \text { el }}\right|>\left|\varphi_{1 \text { com }}\right|_{\lambda_{2}=0.5},
$$

thus

$$
\left|\varphi_{2 \text { com }}\right|_{\lambda_{2}=1}>\left|\varphi_{2 \text { el }}\right|>\left|\varphi_{2 \text { com }}\right|_{\lambda_{2}=0.5} \quad \text { and } \quad\left|\varphi_{3 \text { com }}\right|_{\lambda_{2}=1}>\left|\varphi_{3 \text { el }}\right|>\left|\varphi_{3 \text { com }}\right|_{\lambda_{2}=0,5},
$$

so

$$
\left|\varphi_{(i) c o m}\right|_{\lambda_{2}=1}>\left|\varphi_{(i) e l}\right|>\left|\varphi_{(i) c o m}\right|_{\lambda_{2}=0.5}
$$

and

$$
E_{\text {s com. }\left(\lambda_{2}=1\right)}>E_{\text {sel }}>E_{\text {scom }\left(\lambda_{2}=0.5\right)}
$$

where the subscript "com" refers to compressed fibers while "el" refers to elongated fibers.

The calculated exemplary maximum values of components of longitudinal strains and strain intensity for the bending angle $\left(k \alpha_{g}=180^{\circ}\right)$ are

$$
\begin{aligned}
& \left|\varphi_{1 \text { com }}\right|_{\lambda_{2}=1} \approx 0.3522, \quad\left|\varphi_{1 \text { el }}\right| \approx 0.2364, \quad\left|\varphi_{1 \text { com }}\right|_{\lambda_{2}=0.5} \approx 0.1691, \\
& \left|\varphi_{2 \text { com }}\right|_{\lambda_{2}=1} \approx 0.0651, \quad\left|\varphi_{2 \text { el }}\right| \approx 0.0371, \quad\left|\varphi_{2 \text { com }}\right|_{\lambda_{2}=0.5} \approx 0.0312,
\end{aligned}
$$




$$
\begin{aligned}
& \left|\varphi_{3 \text { com }}\right|_{\lambda_{2}=1} \approx 0.2871, \quad\left|\varphi_{3 \text { el }}\right| \approx 0.2002, \quad\left|\varphi_{3 \text { com }}\right|_{\lambda_{2}=0.5} \approx 0.1378, \\
& \left|\varphi_{(i) \text { com }}\right|_{\lambda_{2}=1} \approx 0.3752, \quad\left|\varphi_{(i) e l}\right| \approx 0.2553, \quad\left|\varphi_{(i) \text { com }}\right|_{\lambda_{2}=0.5} \approx 0.1801 .
\end{aligned}
$$

thus

From Fig.4 it follows that the quotient $\left(E_{\mathrm{s}} / W^{p}\right)$ decreases as the bending angle $k \alpha_{g}$ (and strain) increases. This value is less in the layers subjected to compression for $\lambda_{2}=1$, and greater for $\lambda_{2}=0.5$, in comparison with the layers subjected to tension. The explanation of such a phenomenon is the following. For the given bending angle $k \alpha_{g}$, inequalities (4.4) are satisfied, and as plastic strains increase (it is proved by almost all experiments for large deformations occurring while tube bending), a decrease of the quotient $\left(E_{S} / W^{p}\right)$ is observed. Variation of the curves in Fig.4 is similar to those reported in literature (Adam et al., 1978; Bever et al., 1973; Chrysochoos et al., 1989; Oliferuk et al., 1993; 1995; 1996; 1997).

Within large deformations (except the initial stage), the following implications arise

when

$$
k \alpha_{g} \uparrow \text {, then: }\left(\varphi_{i} \equiv e_{(i)}^{p}\right) \uparrow,\left(E_{s} \mathrm{I} W^{p}\right) \uparrow, Y \uparrow \quad \text { and } \quad\left(E_{s} / W^{p}\right) \downarrow \text {, and } R_{z(t) T} \downarrow
$$

where: $R_{z(t) T}-$ creep resistance of the material for time and temperature $T$.

At the initial stage of deformation, for example to $\sim 4 \%$, for $00 \mathrm{H} 19 \mathrm{~N} 17 \mathrm{Pr}$ steel and some other metals (see e.g., Chrysochoos et al., 1989; 1989; 1992; Oliferuk et al., 1993; 1995; 1996 and Oliferuk, 1997), the maximum values of the quotients $\left(E_{s} / W^{p}\right)$ and $\left(d E_{s} / d W^{p}\right)$ were observed, depending on the deformation degree.

In Fig.5, the rates $\left(d E_{s} / d k \alpha_{\mathrm{g}}\right)$ of storage of plastic deformation energy depending on the bending angle $k \alpha_{g}$ are shown. The curves for the layers subjected to compression are of the ascending character in all the bending angle range; in the layers subjected to tension they are of the same character only for $\left(k \alpha_{g} \leq 150^{\circ}\right)$. Thus, we can talk about "acceleration" of the energy storage process in the layers subjected to compression as the bending angle increases. In the layers subjected to tension such an acceleration is valid only for a ( $k \alpha_{g} \leq$ $\left.150^{\circ}\right)$. For $\left(k \alpha_{g}>150^{\circ}\right)$ the energy storage rate is almost constant (in this range, the graph is almost constant).

Figure 6 shows changes of the ability to store plastic deformation energy $\left(d E_{s} / d W^{p}\right)$ in the layers subjected to tension and compression depending on the bending angle $\left(k \alpha_{g}\right)$, in measures of logarithmic strains. In the case of large deformations, the presented values and histories of the curves variability are comparable with the test results obtained by (Oliferuk et al., 1993; 1995; 1996 and 1997). At the initial stage of strains (to $\sim 4 \%$, which corresponds to the bending angle $k \alpha_{g} \sim 20^{\circ}$ then for $k \approx 1$ we have $\alpha_{g} \sim 20^{\circ}$, and for $k \approx 2$ we have $\alpha_{g} \sim 10^{\circ}$ ), there is no maximum and the calculated curves in Figs 4 and 6 are monotonically decreasing. It can be seen that for the bending angles $k \alpha_{g}$ greater than $\sim 10^{\circ}$, the history of decreasing $d E_{s} / d W^{p}$ is more intense (values of $d E_{s} / d W^{p}$ decrease more quickly) than in the case of experiments made by Oliferuk et al. $(1993 ; 1995 ; 1996)$ and Oliferuk (1997).

The initial values (i.e., for $\left.k \alpha_{g}=0^{\circ}\right)$ of the curves $\left(E_{s .} / W^{p}\right)$ and $\left(d E_{s} / d W^{p}\right)$ were obtained by introduction of the de l'Hospital rule to Eq.(4.5). The procedure is as follows

$$
\lim _{k \alpha_{g} \rightarrow 0^{0}} Q=\lim _{k \alpha_{g} \rightarrow 0^{0}} \frac{E_{s}\left[\varphi_{(i)}\left(\alpha_{g}\right)\right]}{W^{p}\left[\varphi_{(i)}\left(\alpha_{g}\right)\right]}=q_{0} .
$$

The expression (5.3) has uncertainty of $\left(\frac{0}{0}\right)$ type. Using the expressions describing geometry of deformations of the tube subjected to bending: (2.1), (2.2.), Eqs (3.2) or (3.3) and (4.1), (4.2), and using the de l'Hospital rule, after transformations we have

$$
q_{0}=2 B_{0} C n \varphi_{0}^{n-1}=2 B_{0}{ }^{*} C n \rho_{0} \varphi_{0}^{n-1}
$$

where

$$
B_{0}=\rho_{0} B_{0}{ }^{*} \quad \text { and } \quad B_{0}{ }^{*} \approx 1.128 \times 10^{-5}\left[\frac{J}{g(M P a)^{2}}\right] \text {. }
$$


Such an initial value of the quotients: $\lim \left(E_{s} / W^{p}\right)$ and $\lim \left(d E_{s} / d W^{p}\right)$ is $q_{0} \approx 0.716$ or $q_{0}(\%) \approx 71.6 \%$.

Similarly, using the expressions describing the geometry of the tube subjected to bending (2.1), (2.2), Eqs (3.2) or (3.3), and (4.1), (4.2), for the case of a cylindrically linear dependence $E_{s}$ on the of yield stress analysed by Chrysochoos et al. $(1989 ; 1989 ; 1992)$, Soós and Badea (1997) from Eq.(4.5), after some transformations, we obtain

$$
q_{0}=\frac{n}{b_{0} \cdot \varphi_{0}} .
$$

The expression (4.5) and its specific forms (4.6) or (4.7), can be applied for determination of the material constant $B_{0}$ or the coefficient of proportionality $b_{0}[4,22]$, if the experimental value of $q_{0}$ is known. The quantity $q_{0}$ can be a measure of the initial internal thermodynamical force $\pi_{0}$, when the corresponding internal parameter is the plastic strain work (Śloderbach and Rechul, 2006). It means that the force $\pi_{0}$ is a macroscopic (phenomenological level) measure of internal stresses of mode III (so-called submicroscopic stresses) in the material (Cottrell, 1964; Perzyna, 1978).

The method allows determining SEPD during plastic deformation of metals and their alloys (see Fig.2). The results obtained are precise, and there is no need to perform expensive and time-consuming experiments. We must only know the experimental hardening curve for the given material (metal or alloy) and the determined value of the coefficient $q_{0}$; we should also apply the expressions (3.1), (3.2) or (3.3), and (4.6) or (3.1), (3.2) or (3.5) and (4.7) in a proper way.

\section{On the importance of energy stored during cold tube bending}

According to Adam and Wolfenden (1978), Bever et al. (1973), Oliferuk (1997), Śloderbach and Rechul (2006), SEPD causes recovery and recrystallization in metals and their alloys. According to Adam and Wolfenden (1978), Bever et al. (1973), Oliferuk et al. (1996), Oliferuk (1997), SEPD also influences the formation of nuclei of new structures on the grain boundaries (nucleation) and their growth. Thus, it influences kinetic processes in plastically deformed metals and their alloys. SEPD initiates, intensifies and influences processes of internal matter (atoms or particles) diffusion along the grain boundaries and along the volume (lattice diffusion), or usually both types of matter diffusion transport at the same type.

Processes of internal matter diffusion are the factors generating high-temperature creep (above $0.4 \div 0.7 T_{m}$, where $T_{m}$ - melting point) reducing strength of many elements (for example, bends of pipelines and other tube installations) of devices applied in thermal power engineering, chemical and petrochemical industries, food industry and other. Additional energy delivered, for example, to the external layers of the bend subjected to tension can generate and intensify internal physical and chemical processes, also destructive creep. It is obvious that dislocation or diffusion creep inside materials at the temperatures higher than $0.3 \div 0.5 T_{m}$, is a physical mechanism responsible for durable and destructive deformations of pipelines and other tube installations working at higher temperatures. At the phenomenological level (macroscopic description) the following hypothesis can be assumed: SEPD collected in the body reduces activation energy, and increases diffusion of atom stream according to the first Fick law, and increases the rate of durable creep deformation according to the Arrhenius or Weertman laws (Cottrell, 1964). According to the Arrhenius laws, reduction of the activation energy level causes a reduction of the material life under creep and constant stress. Plastic deformation in metals and alloys generates not only the energy stored but, also generates internal stresses (Bever et al., 1973; Cottrell, 1964). These stresses strongly influence the life of many elements and their properties. As an example, we can show a situation when internal stresses are summed with the stresses coming from external forces, causing a decrease of the element load capacity. In order to prevent some internal destructive processes caused by large cold plastic deformations occurring while tube bending at bending machines, it is recommended to perform it at higher temperatures. Depending on the requirements and possibilities, we can chose hot bending, semi-hot bending and bending with preheating (Kocańda, 1998). At higher temperatures, many phenomena or processes take place, which do not proceed (or proceed more quickly) at low temperatures, for example structure homogenizing, SEPD emission during recrystalization, annealing, recovery. 
Let us note that the austenitic steel $00 \mathrm{H} 19 \mathrm{~N} 17 \mathrm{Pr}$ has very good physical and mechanical properties, its ability to undergo plastic deformation and hardening is high. It is easy to make bends of that steel while cold bending (even with the least bending radii $R \approx d_{\mathrm{ext}}$ ). However, strength of these bends in the pipelines working at higher temperatures can be unfavourable because their service life can be shorter than the life of boiler or tube steels, because the storage ability of SEPD of austenitic steels is much higher than that of boiler or tube steels. As an example, we can consider boiler steel K10 analysed by Śloderbach and Rechul (2000). Its maximum density of SEPD per mass unit at the top of the layers subjected to tension after cold bending at $\left(k \alpha_{g}=180^{\circ}\right)$ is $E_{\mathrm{s}(\mathrm{K} 10)} \approx 0.953[\mathrm{~J} / \mathrm{g}]$ (see Fig.7), and in the considered austenitic steel is more than four times greater, $E_{s \text { (aus) }} \approx 4.2[\mathrm{~J} / \mathrm{g}]$, (see Fig.3, the graph in the middle). Thus

$$
n_{\text {(aus.) }}>n_{(\mathrm{K} 10)} \quad \text { and } \quad E_{\mathrm{s}(\text { aus })}>E_{\mathrm{s}(\mathrm{K} 10)}
$$

where: $n_{\text {(aus.) }}-$ coefficient of hardening for the austenitic steel 00H19N17Pr,

$n_{(\mathrm{K} 10 .)}-$ coefficient of hardening for boiler steel K10.

The following material quantities in Eqs (3.1), (3.2)-(3.4) characterize the boiler steel (K10): $C \approx 550$ $\mathrm{MPa} \varphi_{0} \approx 0.016, n_{(\mathrm{K} 10)} \approx 0.2, \rho_{0} \approx 8.0 \times 10^{3}\left[\mathrm{~kg} / \mathrm{m}^{3}\right], B_{0} \approx 6.2 \times 10^{-5}[\mathrm{MPa}]^{-1}$, Young's modulus $E \approx 2.02 \times 10^{5}$ $\mathrm{MPa}$ and $\gamma_{0} \approx 25$.

The dimensionless material constant $\gamma_{0}$ is connected with the coefficient $B_{0}$ according to Bever et al. (1973) by the following expression

$$
B_{0}=\frac{\gamma_{0}}{2 E}[\mathrm{MPa}]^{-1}
$$

The results of calculations of SEPD for K10 steel are presented in Fig.7. They have been obtained by an introduction of suitable material quantities to Eq.(3.1), then expressions (2.1), (2.2), (3.3) have been applied.

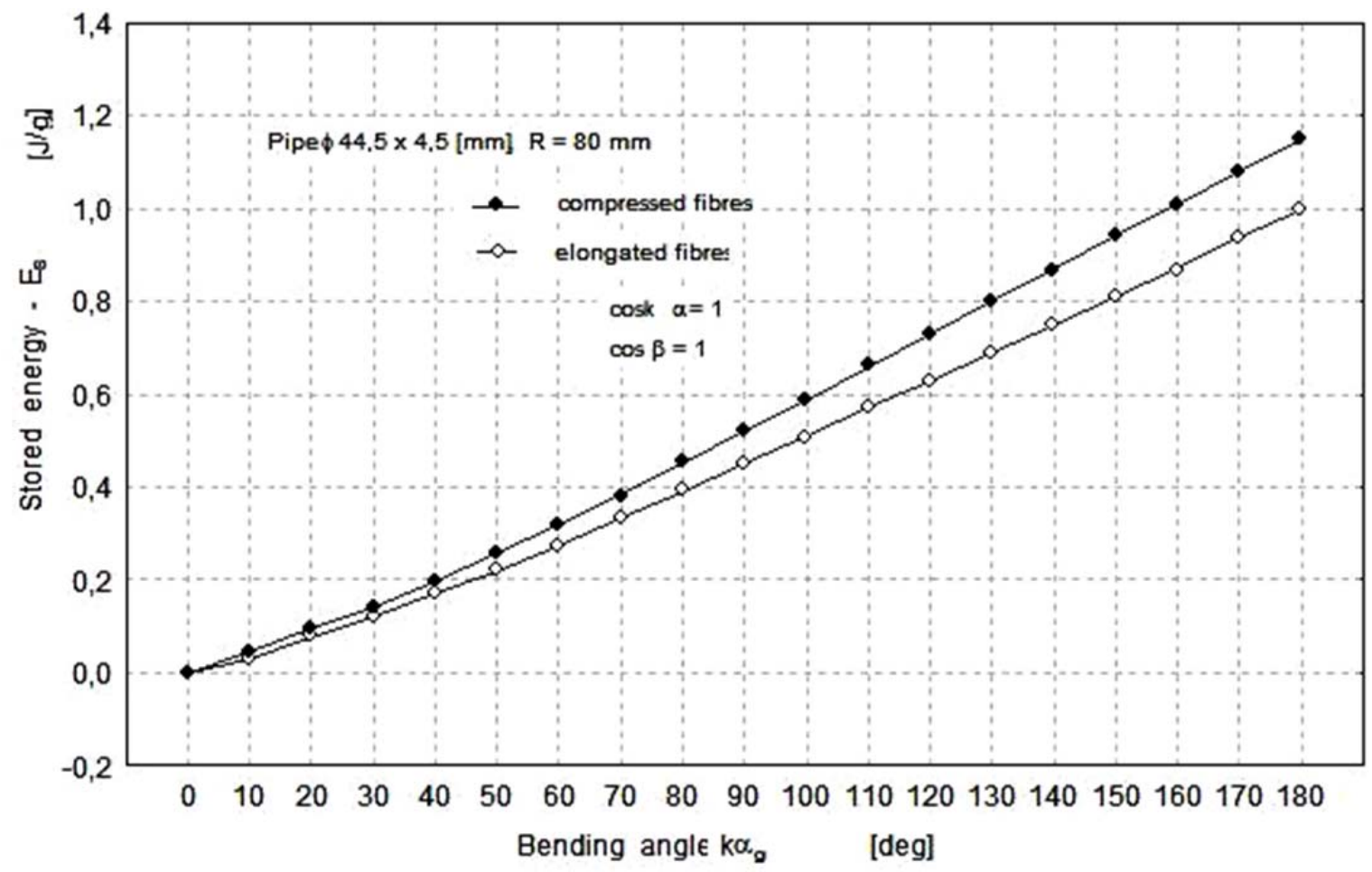

Fig.7. Variation of the stored energy density for $\lambda_{i}=1$ : in stretched layers $\left(\lambda_{1}=1\right)$ and compressed layers $\left(\lambda_{2}=1\right)$ as dependent on bending angle $k \alpha_{g}$ in the bending operation involving the $44.5 \times 4.5 \mathrm{~mm}$ pipe made of boiler steel (K10). 
Figure 7 shows it appears that in the layers subjected to compression, the values of SEPD for $\left(\lambda_{2}=1\right)$ are greater than those in the layer subjected to tension for $\left(\lambda_{1}=1\right)$. It results from strain mechanics and geometry of deformation distribution in the tube bending processes at bending machines, described by expressions (2.1) and implications resulting from Eq.(5.1). Thus

when

$$
\left|\varphi_{(i) \operatorname{com}}\right|_{\lambda_{2}=1}>\left|\varphi_{(i) e l}\right|_{\lambda_{1}=1}, \quad \text { then } \quad E_{\text {scom }\left(\lambda_{2}=1\right)}>E_{\text {sel }\left(\lambda_{1}=1\right)} .
$$

The remaining parameters of the bending process, such as tube dimensions, the bending radius and the bending angle are the same as those for the austenitic steel $00 \mathrm{H} 19 \mathrm{~N} 17 \mathrm{Pr}$.

Tube bending for bends of pipelines (made of the boiler steel K10) with the wrapping method at a rotational former and with the use of a mandrel in the layers subjected to tension can be characterized (see Śloderbach, 1999; Śloderbach and Rechul, 2000) as follows:

a. a loss of stability in the dissipated form (Marciniak, 1971) for the uniaxial tension. Then $\varphi_{(i)} \approx 0.184$, and for this state $E_{s} \approx 0.788[\mathrm{~J} / \mathrm{g}]$,

b. a loss of stability in the located form (initiation of the plane strain state under the plane stress state (ElSebaie, 1972; Marciniak, 1971). Then $\varphi_{(i)} \approx 0.215$, and $E_{s} \approx 0.862[\mathrm{~J} / \mathrm{g}]$ corresponds to this state,

c. a state where the longitudinal strain $\varphi_{1}$ reaches (at a given point) the value corresponding to the strain $A_{5}$. Then, $\varphi_{(i)} \approx 0.236$, and $E_{s}$ calculated to that moment $\approx 0.901[\mathrm{~J} / \mathrm{g}]$,

d. the maximum strains in the bending zone are obtained when the bending angle $\left(\alpha_{0}=k \alpha_{g}=180^{\circ}\right)$. Then $\varphi_{(i)} \approx 0.255$, and $E_{s} \approx 0.935[\mathrm{~J} / \mathrm{g}]$. This value is more than four times less than the value calculated for the austenitic steel (see the central graph in Fig.3).

For the austenitic steel $00 \mathrm{H} 19 \mathrm{~N} 17 \mathrm{Pr}$ and for the same tube dimensions and the bending radius $\left(R=1.8 \times d_{\mathrm{z}}\right)$, such characteristic states $(\mathrm{a}-\mathrm{c})$ do not occur because the value of the hardening coefficient (see Eq.(3.1) in Chapter 3) is high $(n>0.5)$. It causes that the condition excluding such states, $\varphi_{(i)}<\varphi_{(i)}$ adm , is satisfied (El-Sebaie, 1972; Marciniak, 1971; Śloderbach and Rechul, 2000), because the value of $\varphi_{(i) \mathrm{adm}}$ (the subscript adm means admissible) is similar to the hardening coefficient $n$ for that steel, $n \approx 0.5$ (Marciniak, 1971; Śloderbach and Rechul, 2000). Such characteristic states can occur while tube bending at bending machines with smaller bending radii, for example $R<\left(1 \times d_{\mathrm{z}}\right)$ (Śloderbach and Rechul, 2000).

\section{Final remarks and conclusions}

1. The approximate calculation results presented in this paper confirm that SEPD increases, and its ratio to the plastic strain work and ability to store energy decrease as plastic strain increases (in the considered tube cold-bending at bending machines it corresponds to an increase of the bending angle $\alpha_{g}$ ).

2. If we have materials that work at elevated temperatures, then we must prevent grain disintegration caused by cold-working, because a great number of grain boundaries intensifies the matter diffusion along the grain boundaries. It is obvious that a positive evaluation of immediate strength of the material cannot be a criterion of evaluation of strength and work at elevated temperatures. A lack of material cracking while plastic cold-working (while tube bending at bending machines for elbows of pipelines and other thermal tube installations) does not provide such good creep resistance. In the case of creep (especially diffusion creep) the area of the most disintegrated crystalline structure at the top layers subjected to tension seems to be the most dangerous.

3. Hot bending of metal tubes requires lower bending forces and allows performing annealing (for example, normalizing) together with bending. Thus, a suitable internal structure of the material, for example, coarse grained, more resistant to high-temperature creep could be obtained, because the creep rate is inversely proportional to the second or third power of the grain size (Bever et al., 1971; Cottrell, 1964). 
4. In order to provide higher strength and creep resistance of the considered elbows made of austenitic steel, we must perform a suitable heat treatment, or perform bending under elevated temperatures (hot bending, semi-hot bending or bending with preheating), but such technology is more expensive.

5. For the case of cylindrical shells the problem of decohesive carrying capacity under combined loading has been already analysed (Życzkowski and Tran, 1997).

\section{References}

Adam C.M. and Wolfenden A. (1978): The influence of microstructure on the energy stored in deformed aluminium and aluminium alloys. - Acta Metallurgica, vol.26, pp.1307-1315.

Bever M.B., Holt D.L. and Titchaner A.L. (1973): The stored energy of cold work. - Progress in Materials Science, vol.17, Oxford, Pergamon Press.

Buchdahl H.A. (1966): The concepts of classical thermodynamics. - Cambrigde Univ. Press.

Chrysochoos A., Maissonneuve O., Martin G., Caumon H. and Chezeaux J.C. (1989): Plastic and dissipated work and stored energy. - Nuclear Engineering and Design, vol.114, Notrh-Holland, Amsterdam, pp.323-333.

Chrysochoos A. and Martin G. (1989): Tensile test microcalorimetry for thermomechanical behaviour law analysis. Materials Science and Engineering, A 108, pp.25-32.

Chrysochoos A. and Belmanjoub F. (1992): Thermographic analysis of thermomechanical couplings. - Archives of Mechanics, vol.44, No.1, pp.55-68.

Cottrell A.H. (1964): The Mechanical Properties of Matter. - New York: John Willey and Sons.

El-Sebaie M.G. and P.B. (1972): Plastic instability conditions in the deep-drawing of a circular blank of sheet metal. Int. J. Mech. Sci., vol.14, pp.535-556.

Franz W.D. (1961): Das Kalt-Biegen von Rohren. - Berlin: Springer-Verlag.

Franz W.D. (1969): Numerisch gesteuerte Rohrkaltbiegemaschinen. - Werkstatt und Betrieb, Heft 9/69.

Gadaj S.P., Nowacki W.K. and Pieczyska E. (1996): Changes of temperature during the simple shear test of stainless steel. - Archives of Mechanics, vol.48, 4.

Kocańda A. (1998): Termomechanical bulk forming of steel. - Proceedings of the Riso International Symposium on Metallurgy and Materials Science, PRISEA, pp.1-97.

Marciniak Z. (1971): Limit Deformations in Sheet Metal Stamping. - Warszawa: WNT.

Marciniak Z. and Konieczny A. (1987): Modelling the variation of the yield stress within the temperature range typical for cold and warm metal forming. - J. Mech. Work. Technology, vol.15, pp.15-37.

Oliferuk W., Świątnicki W.A. and Grabski M.W. (1993): Rate of energy storage and microstructure evolution during the tensile deformation of austenic steel. - Materials Science and Engineering, A 161, Elsevier Science S.A., pp.5563.

Oliferuk W., Świątnicki W.A. and Grabski M.W. (1995): Effect of the grain size on the rate of energy storage during tensile deformation of an austenitic steel. - Materials Science and Engineering, A 197, Elsevier Science S.A., pp.4958.

Oliferuk W., Korbel A. and Grabski M.W. (1996): Mode of deformation and the rate of energy storage during uniaxial tensile deformation of austenitic steel. - Materials Science and Engineering, A 220, Elsevier Science S.A., pp.123128.

Oliferuk W. (1997): Energy storage process and its relation to material structure in austenic steel tested in simple tension. (in Polish) - IFTR Reports - Polish Academy of Sciences, No 11/1997, Warszawa.

Perzyna P. (1978): Thermodynamics of Inelastic Materials. - Warszawa: PWN.

Raniecki B. and Sawczuk A. (1975): Thermal effects in plasticity. Part I: Coupled theory. - ZAMM, vol.55, pp.333341. 
Raniecki B. (1977): Problems of applied thermoplasticity [in Polish]. - IFTR-Reports, No.29, Warszawa.

Soós E. and Badea L. (1997): A new theory of the stored energy in elasto-plasticity and the torsion test. - Eur. J. Mech., A/Solids, vol.16, No.3, Gauthier-Villars, pp.467-500.

Śloderbach Z. (1983): Generalized coupled thermoplasticity. Part I. Fundamental equations and identities. - Archives of Mechanics, vol.35, No.3, Warszawa, pp.337-349.

Śloderbach Z. (1999): A model of deformation geometry in pipe bending processes. - Engineering Transactions, vol.47, pp.3-20.

Śloderbach Z. and Rechul Z. (2000): Effect of strain hardening and normal anisotropy on allowable values of strain and stress in pipe-bending processes. - Journal of Theoretical and Applied Mechanics, PTMT I S, No.4, vol.38, Warszawa, pp.843-859.

Śloderbach Z. and Rechul Z. (2006): A thermodynamic approach to the stored energy concept. - Journal of Technical Physics, vol. XLVII, No.2, pp.83-102.

Życzkowski M. and Tran L.B. (1997): Interaction curves corresponding to the decohesive carrying capacity of a cylindrical shell under combined loading. - Int. J. Plasticity, vol.13, pp.551-570.

Received: October 12, 2012

Revised: January 17, 2013 